\title{
Hunterian Oration
}

\section{Hunter's legacy and surgical training and competence in the 21st century*}

\author{
Charles SB Galasko \\ Department of Orthopaedic Surgery, Hope Hospital, Salford, UK
}

\begin{abstract}
John Hunter's many contributions to surgery include the development of the scientific approach and possibly the first use of evidence-based medicine. This oration, concentrates on two other areas - first, some of his contributions to orthopaedics and secondly past, present and future surgical training and competence.
\end{abstract}

Key words John Hunter - Orthopaedics - Surgical training

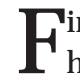
rst, Mr President, I want to thank you for the great honour that you have bestowed upon me and my specialty in inviting me to deliver the 114th Hunterian Oration. I understand that I am the first orthopaedic surgeon to be invited to do so. I am acutely aware of the high standard my predecessors have set.

Many things have been written and said about John Hunter and his contributions to surgery including the development of the scientific approach. He is probably the first person to have used evidence-based medicine. He linked pathological changes and surgical procedures. He taught routine postoperative monitoring and the importance of recording outcome and sharing results, the predecessor of modern audit. In this oration, I want to concentrate on two other areas - first, some of his contributions to orthopaedics and secondly surgical training and competence.

The term orthopaedics was first coined in 1741 by Nicholas Andre in his book Orthopaedia or the Art of Correcting and Preventing Deformities in Children. The word comes from two Greek words orthos meaning straight and paedion child. At that time, John Hunter was age 13. The term orthopaedics was not in use during John Hunter's lifetime.
John Hunter's contribution to orthopaedic surgery

John Hunter's contributions to orthopaedics can be considered in two groups - clinical and pathological descriptions and his experimental work. The clinical and pathological descriptions included infection; fractures; dislocations; disorders of joints; dysplasias, rickets and deformities; tumours and muscle contractures. His experimental work included tendon healing, bone growth, fracture healing and the trabecular structure of bone.

His museum included a dramatic demonstration of the deformity associated with progressive scoliosis (Fig. 1). Unfortunately, nothing is written about this specimen. Many of his records were destroyed after his death by his brotherin-law Everard Home in the 1820s and it is likely that details of this specimen were lost at that time. Hunter was the first person to describe 'sequestrum' and 'involucrum' in chronic osteomyelitis (Fig. 2), and his specimens demonstrated all the pathological processes that occur with osteomyelitis.

Hunter used models and specimens to teach. The anatomical preparation shown in Figure 3 was designed to teach how the two parts of a fractured patella separate because of the pull of the quadriceps.

* Delivered on the 12th February, 2003

Correspondence to: CarolGalasko@aol.com 
The upper portion of the patella should be brought down as much as we can and the common bandage be applied. It may be imagined that, in the treatment, it is not only necessary to extend the leg, but to lay the thigh at right angles with the body; but from a complete knowledge of all the circumstances, it will appear that this practice is not at all necessary; for as the rectus has a greater power of contraction than extending the leg, so it must also be granted that it has a greater power of relaxation; therefore, it is not necessary to place the leg at right angles with the body.

He taught that if the bone ends were brought together they would unite by bone but if the fracture was not reduced it would heal by 'a kind of tendinous or ligamentous substance', a classical description of a fibrous union (Lectures on the Principles of Surgery, p. 511).

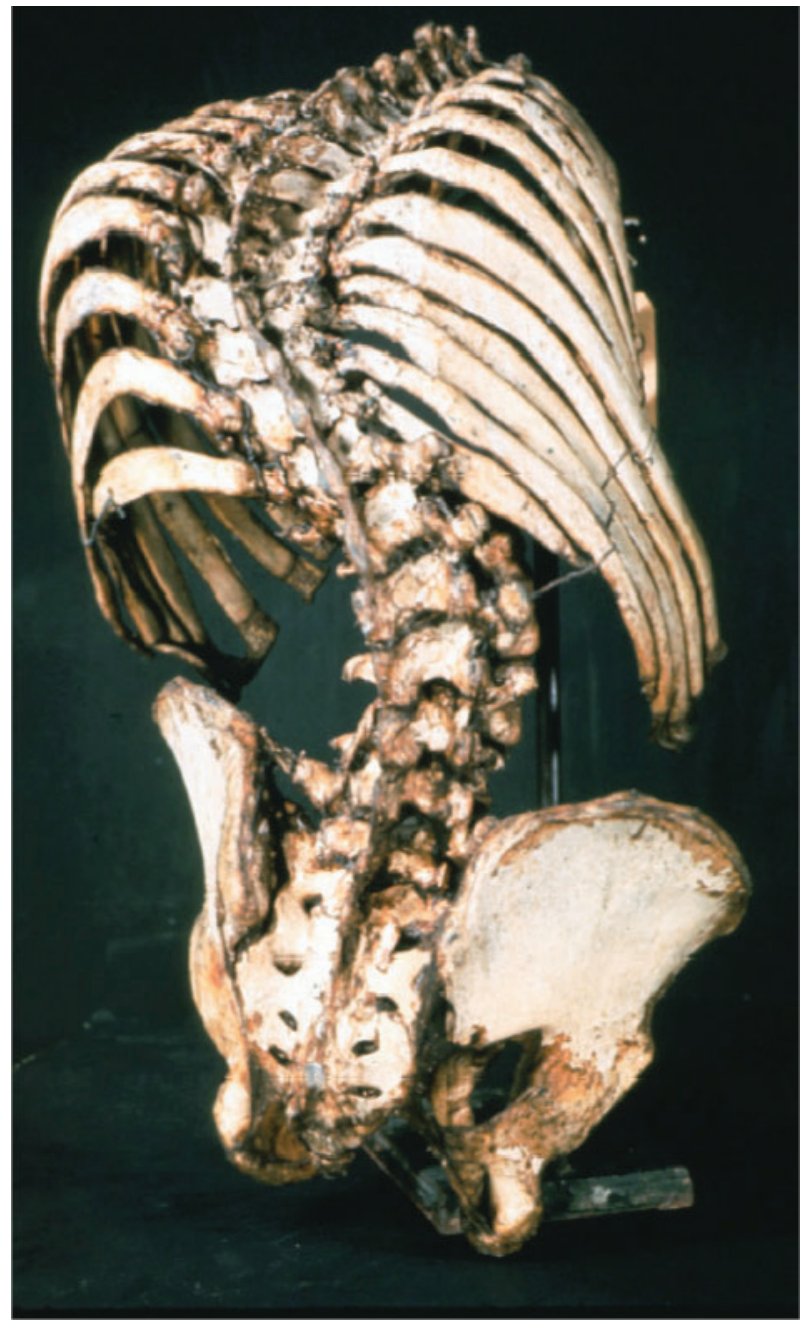

Figure 1 Progressive scoliosis. This specimen demonstrates the skeletal abnormalities associated with progressive scoliosis. (Hunterian Museum, The Royal College of Surgeons of England, specimen P442.)
When union is formed it would be proper to give some passive motion; but voluntary motion is always better, because the will is always sensible how far the powers of the part extend, and will attempt no more; but if force is used to extend the part, all the muscles of which have not their due power, it may be thrown into such a situation as to give an

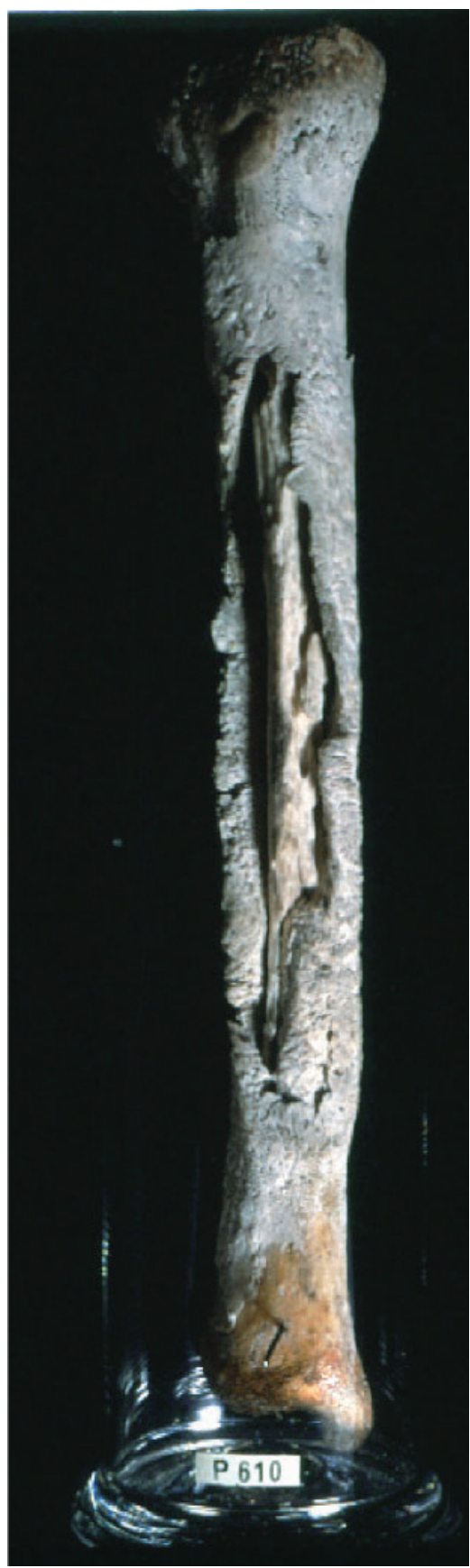

Figure 2 In this tibia most of the diaphysis (shaft) of the femur is dead (the 'sequestrum') and there is extensive involucrum or new bone which has formed around the dead bone and provides the stability. (Hunterian Museum, The Royal College of Surgeons of England, specimen P610.) 
improper action to a weak muscle: the will alone is proper to perform those actions she has determined on herself'

Lectures on the Principles of Surgery, p. 512.

The same applied to a fracture of the olecranon (Fig. 4) and Hunter showed that extension of the elbow reduced the separation.

The olecranon may be considered as a fixed patella, the inserting point of a considerable muscle, and when broken is drawn up as the patella. The immediate treatment is the same; but the consequences are often different, as it should

Figure 3 Anatomical preparation of the bones of a lower limb. The patella has been divided, the two ends being held together by leather (to represent the flexible but inelastic bond forming between the bone ends). The pull of the quadriceps muscle is represented by the spring and shows how the pull of the quadriceps results in separation of the bone ends. (Hunterian Museum, The Royal College of Surgeons of England, specimen P376.)

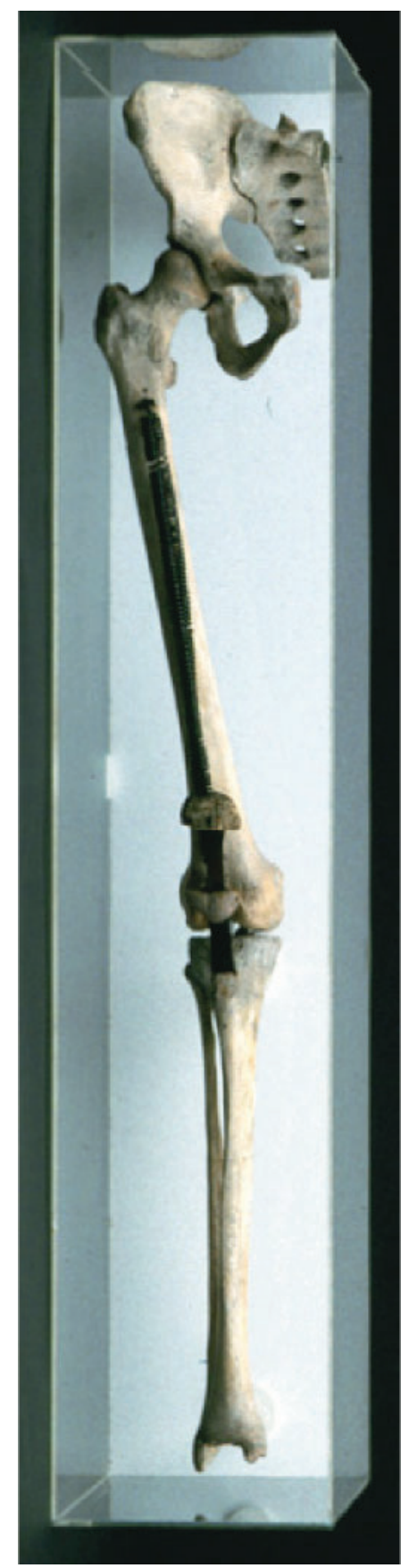

always be united by bony union. The arm should be extended, and kept so; and the upper portion brought down, if up, and retained by a bandage, which will be somewhat similar to those used after bleeding. When soft union has taken place, and bone is beginning, passive motion of the joint should be made. As the union gets stronger, the motion should be increased, but should not be very great, until bony union is completed, as before this it will bend the olecranon over the lower end of the os humeri, and occasion it to make a smaller curve than it should do, even an angle; by which

Figure 4 Specimen of the bones of an upper limb. The olecranon has been divided. The pull of the triceps is represented by the spring. The bone ends have been held together by India rubber to demonstrate the elastic nature of the union. In this specimen, Hunter has shown how the separation of the fragments is reduced by extending the elbow. (Hunterian Museum, The Royal College of Surgeons of England, specimen P377.)

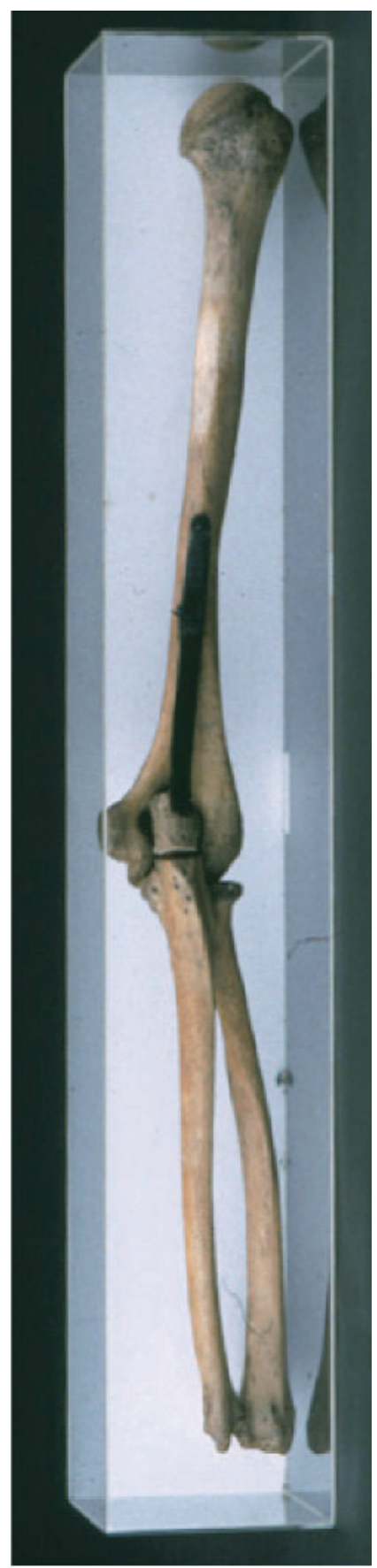




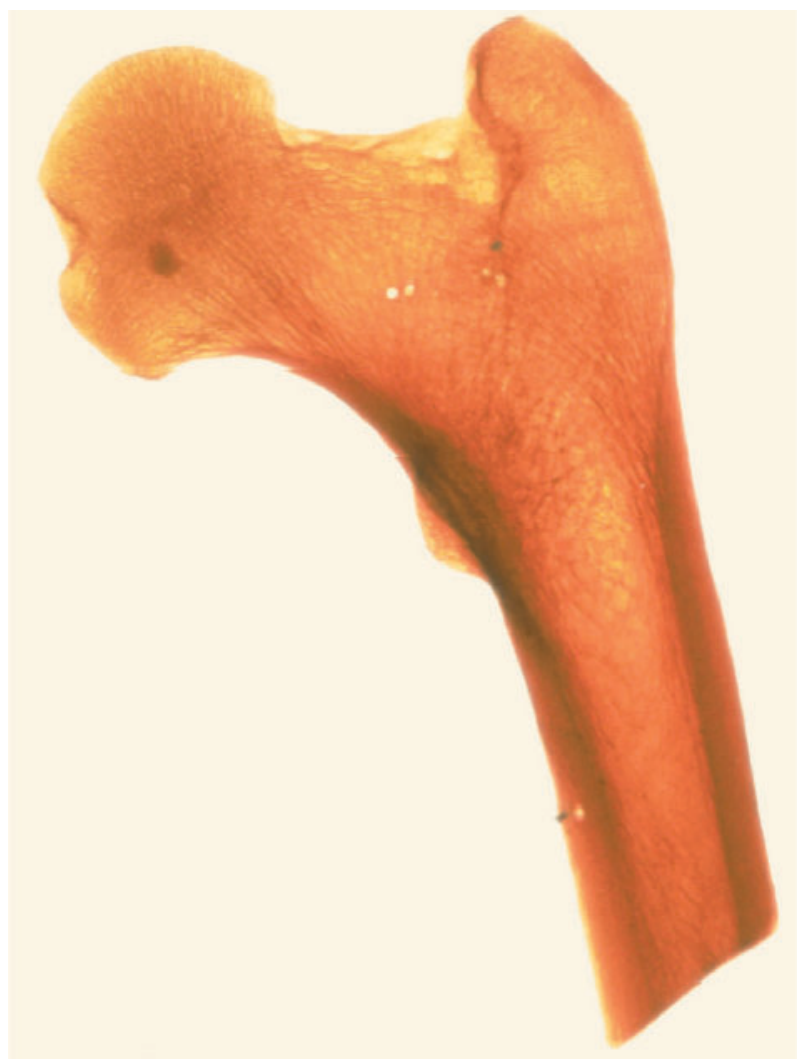

Figure 5 Specimen of femur. Injection studies of bone. (Hunterian Museum, The Royal College of Surgeons of England, specimen P117.)

the full extension will be prevented. This, by proper attention, may be avoided.

Hunter, Lectures on the Principles of Surgery, p. 513.

He described methods of bandaging in an attempt to minimise the separation of the fragments of a fractured patella and of a fracture of the olecranon but, unfortunately, we have no illustration of his bandaging technique.

Hunter was aware of the difference between simple fractures and compound fractures. He was aware of the process of fracture healing:

When a bone is fractured, the periosteum and surrounding cellular membrane concur with the broken surfaces and lining membrane of the bone to pour out a massive lymph (callus), which gradually undergoes successive transformations in structure, until the new-formed part closely assimilates in all respects to the old structure. For the first week or 10 days it is observed to consist of a soft vascular granular-looking mass which gradually assumes, towards the 20th day, a white and cartilaginous aspect, and at the same time diminishes in bulk: from this period to the 40 th or 50th day the diminution of the callus still proceeds, and the process of ossification is now observed to have converted the greater part of it into true bone, although towards the centre of the mass a portion may still remain, which is not fully converted into bone before the exporation of the 4th or 6th months. If at the end of this period the bone is examined, it will be found to be thick and irregular at the point of fracture; the medullary cavity will be found to be obliterated, and the new bone to possess the hardness of ivory. Ulterior changes, therefore, still go on for 2 or 3 years, which at last end in the complete restoration of the external form of bone, as well as the internal medullary cavity and reticulated structure.

Hunter, Lectures on the Principles of Surgery, p. 501.

He was aware of complications of malunion, delayed union and non-union and described pseudarthroses.

John Hunter's studies on bone were outstanding and as significant as much of the research that has been awarded Nobel prizes. He understood that bone was composed of an 'animal substance' which we now know as collagen and 'calcarious earth' which we now know as hydroxy-apatite. He realised that the function of the skeleton was to:

... support the other parts of the body to allow for the different parts being kept at a distance from each other and to be acted upon by the muscles of the body.

He analysed the force transfer in bone and through his injection studies illustrated the trabecular structure of the proximal femur (Fig. 5). This illustration has since been used as the basis for thousands of publications and lectures on bone structure. He realised that bone grew lengthwise at its ends and in diameter by periosteal new bone with endosteal resorption. In his classic experiment shown in Figure 6, he placed two lead shots in the shaft of a tarsal bone of a young chicken. The chicken was killed when it had 'grown old'. The bone had lengthened considerably but there was no increase in the distance between the two lead shots showing that the bone grew from its ends, where we now know the growth plates are sited.

Studies in bone remodelling were carried out by feeding animals on madder, an extract of the root of Rubia tincterium which has been known as a dye since biblical times. He showed that:

... bony matter is deposited on the outside of the bone, the absorbance or removing it from the inner side, otherwise it would become heavy and clumsy, and unfit for motion. Hence I call this the remodelling process for without this combined action of absorption and deposition, the animal could not grow as it does.

He was aware of age-related osteopaenia.

But in the full grown state, it would appear from the circumstances of reddening of the whole bone, by feeding the animal with madder, that bone, although completely formed, yet is changing its earth, and probably every other part. This 


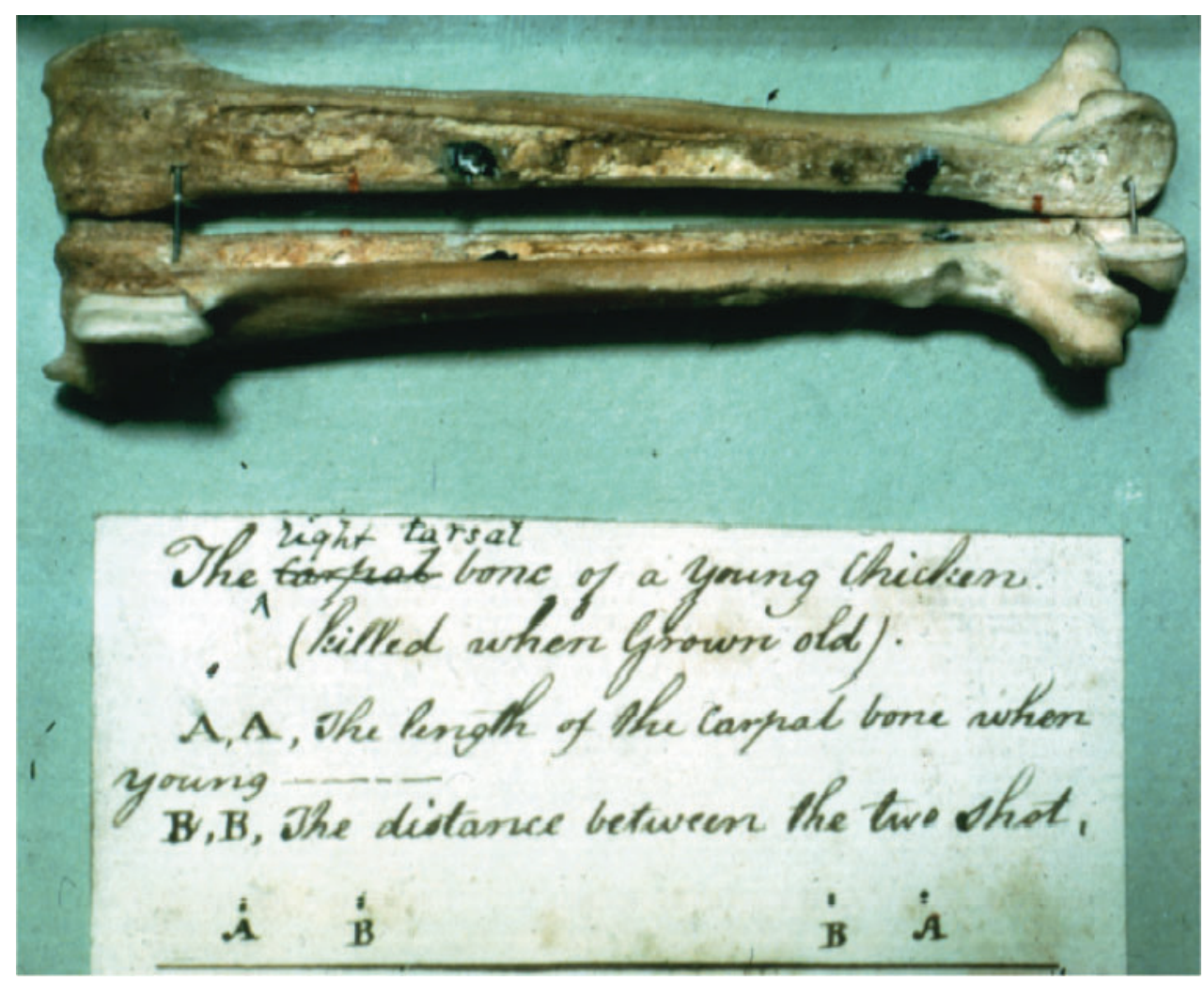

Figure 6 Hunter placed two lead shots in the shaft of a tarsal bone of a young chicken. The chicken was killed when it had 'grown old'. The bone had lengthened considerably but there was no increase in the distance between the two lead shots, indicating that the bone had grown at its ends. (Hunterian Museum, The Royal College of Surgeons of England, specimen A78.)

effect, however, is much slower than in the growing bone. The new matter that is deposited in an old bone is to make up for the waste that it daily going on in it; but in a very old bone the waste is more than the repair.

Unfortunately, madder-stained bones loose their colour in the course of the years and the many preparations that Hunter made to illustrate the process of growth and absorption now show very little trace of red colouration. Fortunately, the drawings of William Bell, John Hunter's assistant, demonstrated the findings (Fig. 7). In this drawing of a femur of a hog, the pink area demonstrates that the bone formation is periosteal.

John Hunter ruptured his tendo-Achilles. His description is classic:

On Thursday morning at 4 o'clock 20th February 1766 I broke my Tendo-Achilles. I was jumping and alighting upon my toes without allowing my heels to come to the ground, by which means I supported the whole weight of my body joined with the velocity in falling, upon the gastrocnemei and solei muscles - these two joined was too much for the tendon, which gave way at once, by which means my heel came to the ground. The snap made by the tendon was heard all over the room. I stood still without being able to make another spring: and the sensation it gave me was if something had struck the calf of my leg; and that the noise was the body which had struck me falling on the floor, and I looked so see what it was but saw nothing. I walked to a chair but could not thrown myselfforwards on my toes on that foot; the calf of the leg was extremely painful and was in a state of a cramp. I endeavoured to take off the cramp by bending the foot, but found that the motion had no effect on the contraction of the muscles of the calf of the leg and upon further examination I found that the Tendo Achilles was broken. ${ }^{1}$

He treated himself not by confining himself to bed as was the usual practice but initially with binding it up with the foot extended (plantar flexed) and the knee a little bent, and avoided walking for some weeks after which he walked with an old shoe fitted with a heel raise and with a strap behind to buckle to a laced bandage. 'When I first began to walk I did not use or move the joint of the ankle'. His treatment was very similar to today's conservative treatment, except that we use more modern materials. Open repair had been attempted before this but with the inevitable infection and failure. 


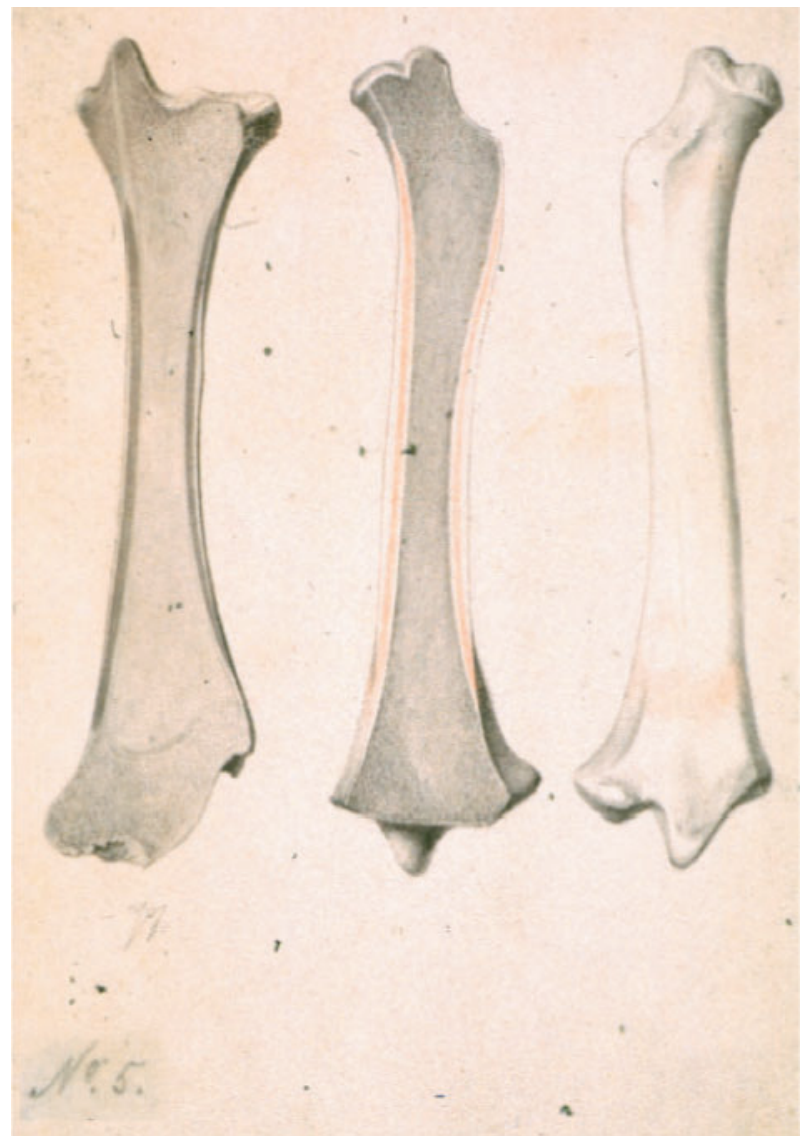

Figure 7 Madder is taken up by bone that is being laid down at the time the animal is given the dye. In this drawing, the pink area shows the madder and hence the new bone is being laid down subperiosteally. (The Royal College of Surgeons of England, Physiological Series no. A105. Drawing by William Bell of the femur of a hog that has been fed on madder.)

He developed an interest in tendon healing and carried out a number of experiments where he divided the tendoAchilles percutaneously with a needle. He showed that the tendon healed by bundles of fibrous tissue. The healing of the tendo-Achilles in an ass is shown in Figure 8.

He did not use percutaneous tenotomy for the treatment of deformity. This operation was first carried out by Frederick Strömeyer of Hannover in 1836. He called this operation 'operative orthopädic'. In 1838, the term orthopaedic operation was introduced into Britain by William Little. Little had suffered from poliomyelitis and was left with an equinus deformity. As part of his education, he spent two years working in Germany. Whilst there, he underwent percutaneous tenotomy, the surgeon being Strömeyer. Little also learnt the technique of percutaneous tenotomy. He was not the first person to carry out the operation in the UK - the first person to do so being JW Whipple of Plymouth who carried out two

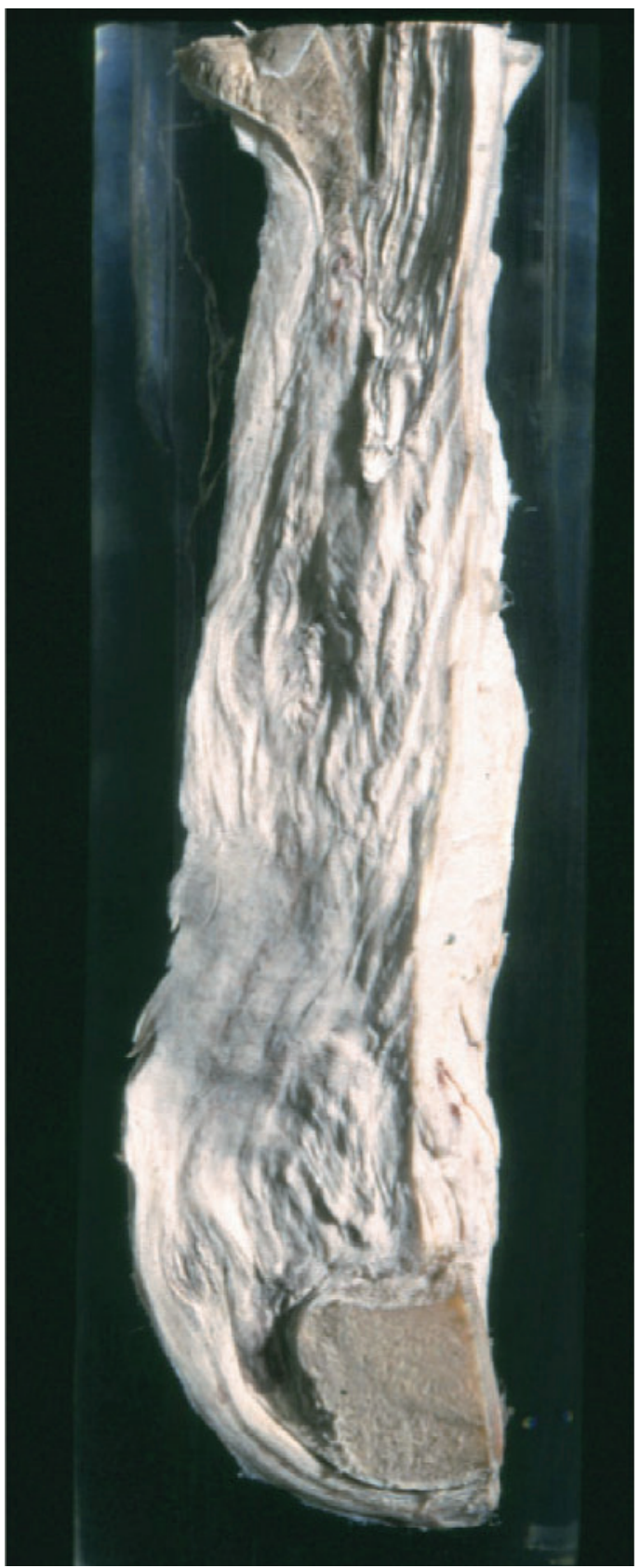

Figure 8 Healing of a divided tendo-Achilles in an ass. Hunter had divided the tendon percutaneously with a needle. He showed that the tendon healed by bundles of fibrous tissue. (Hunterian Museum, The Royal College of Surgeons of England, specimen P110.)

operations for club foot in 1836. Little carried out his first operation in London in 1837.

Hunter also described tuberculosis of the spine, not only as a condition which could kill the patient and produce deformity, but also as a condition that could produce an abscess penetrating through the bony spine 


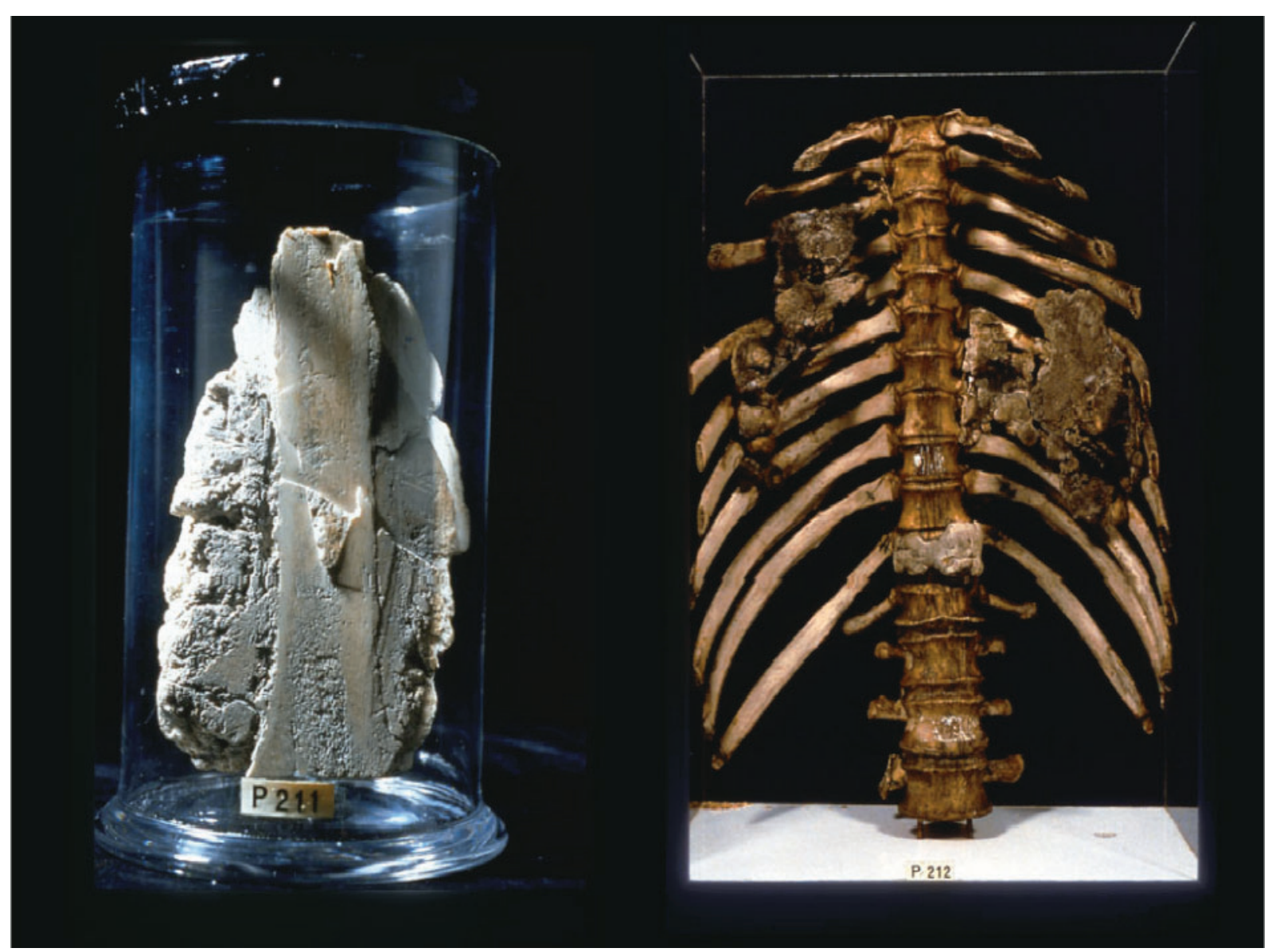

Figure 9 Primary osteosarcoma plus pulmonary metastases which were bony (Hunterian Museum, The Royal College of Surgeons of England, specimens P211 and P212.)

into the spinal canal producing paralysis. He was aware of age-related osteopaenia and his experiences on active service formed the basis of his classical studies on the pathology of inflammation and gunshot wounds. He concentrated on the wounds from musket balls in his treatise Blood, Inflammation And Gunshot Wounds, published the year after his death. His description of pressure and disuse atrophy of bone, as in the specimen showing pressure necrosis of the sternum caused by an aortic aneurysm was probably original. He described postmenopausal osteoporosis associated with kyphosis, ossification of the anterior longitudinal ligament of the spine and traumatic chondromalacia of the patella in a policeman who had been injured 6 days before his death.

His collection included the common important tumours of bone. He was aware that osteosarcoma could metastasise to the lungs (Fig. 9) and was aware of the effect that dissemination of a tumour had on the prognosis. In 1793, he described a patient with mammary carcinoma who had originally refused amputation of her breast but:

She returned with a severe cough and shortness of breath, which I did not like, for I had often seen such after the disease had made considerable progress towards the source of the circulation along the armpit and $c$. which I conceived arose from the lungs being affected with the absorbed matter from the tumour as it must circulate first through them before it got to the common circulation; but all this was conjecture, for I had not been able to open such as had had the symptom and seem to die of it. She now came to the resolution of having it removed and I now wished to put it off altogether.

At autopsy, he found pulmonary metastases in this patient. This was probably the first mention of the importance of determining the extent of malignant disease before deciding upon treatment. He was also aware of skeletal metastases. Figure 10 shows a specimen of the proximal femur, distal humerus and skull showing the defects left by skeletal metastases, all the specimens coming from one of his patients (specimens P844, 846, 847, Hunterian Museum, The Royal College of Surgeons of England).

\section{Education and training}

Both William and John Hunter were particularly interested in education. William Hunter stated: 'to acquire 


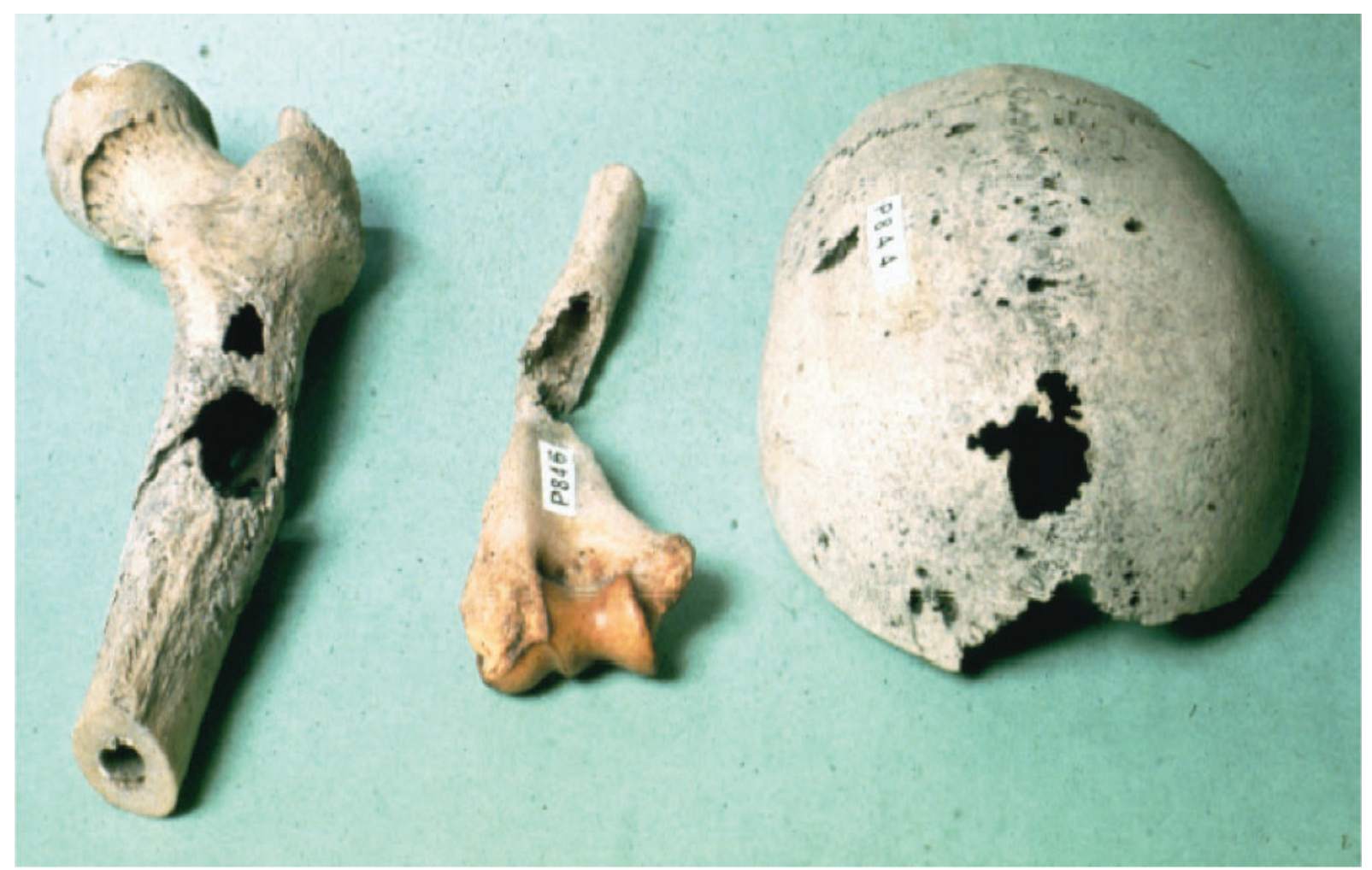

Figure 10 Skeletal metastases. There are lesions in the proximal femur, distal humerus and skull, all the specimens coming from one of his patients. (Hunterian Museum, The Royal College of Surgeons of England, specimens P844, 846 and 847. .)

knowledge and to communicate it to others has been the pleasure, the business and the ambition of my life'. John Hunter indicated: 'my motive in the first place was to serve the hospital (St George's Hospital) and in the second to diffuse the knowledge of the art, that all might-be partakers of it; this indeed is the highest office in which a surgeon can be employed' (quoted by Finch ${ }^{2}$ ).

The effect that John Hunter had on the teaching of others was such that his pupils and apprentices founded hospitals in the provinces and abroad, they formed medical schools and contributed significantly to medical research. Not only was John Hunter the founder of the scientific method in surgery but he played a major role in the development of medical education and training. ${ }^{2-7}$

\section{Definitions}

The following definitions are used in his article:

Competent - this is defined as fit for purpose, adequately qualified and able to integrate the different competencies required. In this context, it means an individual who has all the abilities required to undertake the duties of a consultant surgeon in the National Health Service to an agreed, acceptable standard. It is a standard to be achieved before the issue of a Certificate of Completion of Specialist
Training (CCST; soon to be a CCT - Certificate of Completion of Training) and entry onto the Specialist Register. The division of each competency into knowledge, skills and attitudes is not enough. What is required is the ability to integrate different competencies. It is this integration that is important in judgement and decisionmaking and the totality of the different competencies required that makes a trained surgeon. The Concise Oxford Dictionary defines competent as 'adequately qualified'.

Competencies - this describes the series of abilities that together make up a competent person. It is defined by the Concise Oxford Dictionary as 'ability (to do a task)'.

Skill - this is defined by the Concise Oxford Dictionary as 'expertness, practised ability, facility (in doing something)'.

Knowledge - There are two components, the general or background knowledge that all doctors should possess, plus a more specialised body of knowledge relating to the individual's specific specialty and subspecialty.

Attitudes - The behaviours must be compatible with their expected role. It includes the recognition that healthcare is provided within an organisation and not in isolation. It covers ethical behaviour within the UK healthcare setting and clinical governance. 
Assessment - In this context, assessment is a summative process that collects evidence about the trainee's progress towards a defined goal and involves making a judgement about whether this goal has been achieved. It is primarily a regulatory process and determines when trainees can move from one stage of training to the next and whether they have reached an appropriate standard for certification. It involves a summative approach to determine whether or not particular competencies have been achieved. Although the assessment is a summative procedure, it can also be used as a form of appraisal in that areas of weakness can be fed back to the trainee and the trainer so that attention can be given to overcoming these weaknesses. What is important is the overall competence of the individual which will allow him/her to practice as a consultant surgeon within the National Health Service.

Appraisal - This is a confidential planned review of progress, focusing on achievements and future activity. It allows training needs to be identified and is primarily concerned with development.

Training - In using the word 'training', I am using shorthand for education, training and gaining experience. Education and training are different but both are necessary for a competent surgeon. Education basically implies training of the mind whereas training is more practical in that it implies teaching the skills, knowledge and attitudes required for the particular discipline.

\section{Importance of training and education}

It was Henry Mankin who said that without research in one generation the specialty will not grow, but without training and education in one generation, there will be no specialty. To this one can add that if training and education in one generation is inadequate, patients will suffer for decades to come. Without assessment, incompetence will flourish.

\section{Development of surgical training and competence}

The training required and the assessment of competence has changed markedly since the Company of Surgeons was introduced in 1745. At that time there was no compulsory curriculum, surgeons served an apprenticeship of 7 years and took an oral examination in anatomy and surgery. The examination was only compulsory for Navy and Army surgeons. In the early years of the College, the format was the same but by 1813 requirements were laid down before one could take the Membership Examination, namely that prospective candidates had to have attended one course of anatomical lectures, one course of surgical lectures and had a certificate of attendance at a hospital for at least one year. William Hunter ran a school that provided courses of anatomical and surgical lectures and John Hunter taught in this school for many years.

In 1815, the Apothecaries' Act was passed. As a response, the College in 1819 printed its first curriculum. The apprenticeship gradually fell into disuse and in 1837 a written examination was established for a doubtful pass, it subsequently became part of the examination.

In the 20 years following the Apothecaries' Act, the curriculum increased. In 1822, George IV approved a 6year apprenticeship and a mandatory period of 'walking the hospitals'. In 1843, when the Fellowship of the College was introduced, the time of professional study was decreased to 5 years, for much of the time which was spent as an apprentice had not really been devoted to study. In 1838, an attempt was made to standardise the surgical curriculum throughout the UK and a conference was held between representatives of the Colleges of Surgeons of London, Edinburgh and Dublin to determine what should be the minimum required. The schedule drawn up and agreed to by the representatives of the Colleges was as follows:

Proof of a suitable preliminary education

3 years' study in a recognised school of surgery

21 months' work in a hospital

Dissection during two winter sessions

2 courses of 6 months' lectures in anatomy and physiology

2 courses of 6 months' lectures in surgery

1 course of 6 months' lectures in each of the following

subjects - chemistry, practical physic, midwifery, materia

medica and 25 lectures on forensic medicine.

It was also stipulated that the candidate should be tested in his knowledge of anatomy, physiology, surgery and pathology. Hospitals were to be recognised at the discretion of each College.

From 1839, study in the provincial schools was recognised by the College. In 1843, the Fellowship of the College was introduced. Initially, it was only by nomination but from 1844 it could be taken by examination. The examination included a written paper and an oral examination on surgery, pathology and therapeutics. Operations on cadavers were initially instituted, they were relatively minor, such as tying off the anterior tibial artery, the posterior tibial artery or the radial artery and soon the operative part of the operation fell into disuse. The Membership was for aspiring general practitioner surgeons and the Fellowship was for those involved in teaching. The College was primarily an examining body.

In 1860, the College instituted a two examination system. The first was in anatomy and physiology and was taken at the end of the second winter. The second or final examination was in surgery, surgical anatomy and 


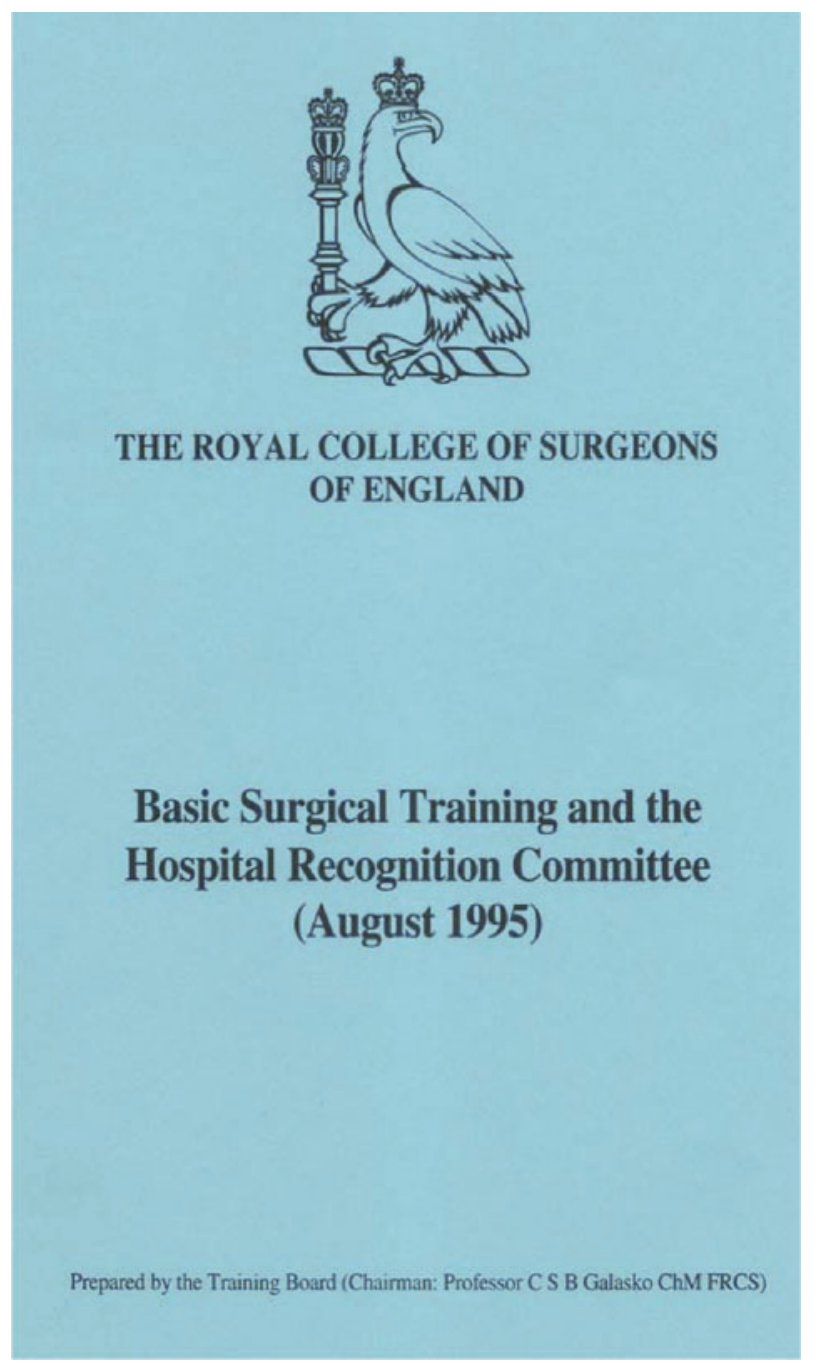

Figure 11 The 'Blue' Book which was published in 1995. It was the first time that the College laid down the requirements for basic surgical training and the recognition of posts suitable for basic surgical training.

surgical pathology and was taken at the end of training. They considered the first examination might be wholly oral whilst the second should be both written and oral. By 1866, it was laid down that the examination of patients should form part of the examination and in 1867 the format of a primary and final examination was introduced. This format did not change for over 100 years.

There was no significant change until 1935 when Sir Holburt Waring queried whether examinations alone were enough to ensure standards in surgical training and asked Members of Council to visit and report on hospitals seeking approval for surgical training. This subsequently led to the development of the Hospital Recognition Committee, which gradually became more influential. In 1959, the Committee on the Training of Surgeons became the Training Board. In 1960, a nation-wide network of Regional Advisors and Tutors was established to guide and assist trainees.

During World War II, it became apparent that hands-on skill training was more important than merely learning by observation. The FRCS did not become compulsory for surgeons until 1948 when the National Health Service was established. It became a compulsory requirement before one could obtain a senior surgical registrar post. It was not compulsory for a consultant appointment. Consultant Appointment Advisory Committees were responsible for recognition of the surgical competence of a consultant. In 1966, the Specialist Advisory Committees were established in each specialty (in co-operation with the Specialist Associations) to ensure that the senior registrars were receiving appropriate training and in 1972 the Certificate of Accreditation was introduced.

In the 1990s, there were significant and rapid changes both in basic and in higher surgical training. The changes in basic surgical training included the introduction of the new MRCS (as opposed to the Old Fellowship examination), based on two years' supervised training, a more flexible choice of rotation during the two years, registration of senior house officers (SHOs), and quinquennial regional visits. Up until that time, hospital visits were supposed to be on a quinquennial basis but were only carried out when a surgical tutor requested one. When I became Chairman of the Hospital Recognition Committee in 1992, I found that some hospitals had not been visited for over 20 years or more. The establishment of the quinquennial regional visits meant that every training hospital would be visited every 5 years. Appraisal and assessment of both trainees and training posts were introduced as well as the concept of an educational contract. The 'Blue' Book (Basic Surgical Training and the Hospital Recognition Committee; Fig. 11) was published in 1995, second and third editions being published shortly afterwards. The third edition was relabelled as The Manual of Basic Surgical Training and was published in 1998. The 'Blue' Book indicated that the aims of basic surgical training were to provide a common trunk of training in the principles of surgery in general and defined in broad terms the competencies required to enter higher surgical training. It indicated the type of posts suitable for a 2-year training programme and the details of a visit of inspection. It detailed the SHOs' timetable for the first time, indicating the minimum number of operating lists, out-patient clinics and pre-operative and postoperative consultant ward rounds that were required for a post to obtain educational approval. It also indicated the requirements for approval of posts in accident and emergency, the role of the College surgical tutor, introduced appraisal of SHOs and assessment of training posts and trainers and detailed the role of the Education Department. 
It was the first time that the College defined the requirements of basic surgical training. It provided the basis for the Intercollegiate Agreement on Guidelines for Basic Surgical Training and it led to Intercollegiate Agreement on assessment. During the 1990s, the College also introduced Career and Flexible Training Advisors. The 1990s saw the introduction of Regional and Subregional Basic Surgical Training Committees whose job it was to oversee basic surgical training in that region. The College also produced the Basic Surgical Training Handbook.

The changes in higher surgical training in the 1990s were even more dramatic than the changes in basic surgical training. They included the introduction of the Intercollegiate FRCS Specialty Examination. Although the examination was introduced in the 1980s, it did not become a compulsory component of surgical accreditation until 1991. The changes also included the 'New Deal', 'Achieving a Balance', and inspection of registrar posts and a more rigorous procedure for appointing career registrars (EL(H)WB/68). Until the 1990s, only senior registrar posts were inspected. There was no supervision of the educational or training aspects of registrar posts. The 1990s also saw the introduction of the Calman training programme with a single grade specialist registrar (SpR) for higher specialist training. In general terms, previous suitable registrar posts, became year 1, year 2 and year 3 training posts and senior registrar posts were converted to year 4 , year 5 and year 6 training posts. The arrangements were different in different specialties. This led to the creation of type 1 training programmes, satisfactory completion of which is one of the requirements for entry onto the Specialist Register (see below) and type 2 programmes which were for overseas trainees but which, on their own, did not lead to a Certificate of Completion of Specialist Training (CCST). The latter was also introduced as part of the new training programme and replaced the previous Certificate of Accreditation. The details were published in the 'Orange' Book (A Guide to Specialist Registrar Training). The draft was published in 1993 and subsequently amended in 1995, 1996 and 1998. It also introduced a new terminology for SpRs - NTNs (those with National Training Numbers), VTNs (those visitors on type 1 training programmes who had visiting training numbers) and FTNs (those visitors who had fixed-term training appointments). The latter were on type 2 training programmes.

An annual assessment (Record of In-Training Assessment, RITA) was introduced as were appraisals at the end of each post.

There was the introduction of the Specialist Register and the Specialist Training Authority of the Royal Medical Colleges whose role was to assess the training and award a Certificate of Completion of Specialist Training (CCST) to those who had satisfactorily completed a type 1 training programme in their specialty. The European Specialist Medical Qualifications Order 1995 came into force in January 1996. The Order implemented the UK's European obligations relating to the training of medial specialists and to the mutual recognition of their qualifications. Under these arrangements, the General Medical Council was required to maintain and publish the Specialist Register. It became a legal requirement for all doctors to be on the GMC Specialist Register before they could take up a substantive consultant appointment but SpRs were allowed to apply for consultant appointments before being admitted to the Specialist Register provided that the date of interview was within 3 months of their expected CCST date. As a response to all these changes, the College produced a Handbook for Surgical Tutors in September 1998, a Handbook for College Assessors in May 1999, and a Handbook for Regional Advisors and Regional Specialty Advisors in June 1999, and the Joint Committee on Higher Surgical Training of the United Kingdom and Ireland produced a new 'Seventh Report' edition of Manual of Higher Surgical Training in the United Kingdom and Ireland in July 1999, and which has recently been updaded (2003).

\section{Current problems}

Despite the tremendous changes that occurred in basic surgical training and higher surgical training in the 1990s, problems still exist as a result of which there will continue to be significant changes in specialist training in this decade.

The main problems currently facing basic surgical training include the gap period between basic surgical training and higher surgical training; inadequate training in some posts; inadequate supervision, appraisal and assessment; the reduction in working hours as a result of which many SHOs spend much more time on call within a shift system leaving them with many fewer hours for training and gaining experience and problems with the provision of training at a time when there is intense pressure on consultants to improve the service and reduce waiting times for out-patients and in-patients.

These problems have affected all surgical specialties. The Academic Board of the British Orthopaedic Association evaluated how these problems affected the education and training of SHOs in trauma and orthopaedics. ${ }^{8} \mathrm{~A}$ questionnaire was sent to all SHOs in the specialty of whom $659(58 \%)$ responded. Of the responders, $26 \%$ did not attend clinics regularly, $28 \%$ did not see nor were taught on new patients, $11 \%$ did not regularly attend the operating theatre, and $30 \%$ were not taught to operate. We found that the education and training was significantly better in regions where there were more Consultants per unit population. de Cossart et al. ${ }^{9}$ also found inadequacies in the teaching of operating skills to SHOs. 
Table 1 Useful hours available for training, education and gaining experience

Prior to Calman; 'New Deal'

Current (post Calman; 'New Deal')

European Working Time Directive (same no. of years in training)

Training reduced to 6 years (basic and higher specialist training)

Training reduced to 5 years

$\begin{aligned} 29,120(100 \%) & \\ 15,498(53.2 \%) & (100 \%) \\ 9378(32.2 \%) & (60.5 \%) \\ 6252(21.5 \%) & (40.3 \%) \\ 5210(17.9 \%) & (33.6 \%)\end{aligned}$

The above does not include 1 year as a pre-registration house officer but does include average of 3 useful hours per night on call.
As a result of the survey, it was recommended that better provision should be made for service needs to ease the tension between service needs and training requirements, that there needed to be better compliance with the recommendations from the Hospital Recognition Committee as laid down in the 'Blue' Book, that job specifications for SHOs needed to be detailed, that SHOs required high quality educational supervision and that most trauma and orthopaedic units should appoint a lead clinician (who is different to the hospital surgical tutor) and who would oversee the education of the SHOs in the specialty. These principles apply to all surgical specialties and not just trauma and orthopaedics. It was also recommended that all $\mathrm{SHO}$ posts should be incorporated into surgical rotations under the auspices of programme directors, that there should be greater one to one contact between the SHO and his/her consultant and that consultant expansion was essential not only to deliver the NHS plan but also to underpin education and training.

This tension between service needs and educational needs is not unique to surgery nor to SHOs. In July 2002, in its publication Implementing 'A New Doctor', the General Medical Council reported that this was a major concern in the education of pre-registration house officers.

The current problems with higher surgical training include a failure to appreciate the amount of supervision needed. Today's year $1 \mathrm{SpR}$ is less experienced than previous registrars (in the pre-Calman training era) and year 4 trainees are less experienced than previous senior registrars. This means that consultants must devote more time to the training aspects than they did in the past. Despite the importance of appraisals, they are not being carried out regularly and the assessments at the end of each training post are often not sufficiently robust. When the assessments are robust there often is a failure to support such assessments of both trainees and training posts.

Above all, the major current problem is pressure on time for training as a result of the tension between training and education requirements and service needs. Because of the pressures to meet waiting list targets, it is usually the training that is sacrificed.

The number of hours available for training and gaining experience has steadily decreased from almost 30,000 hours prior to the introduction of the Calman training programme and 'New Deal' (Table 1), to the current 15,000 hours and which will reduce to under 10,000 hours following the introduction of the European Working Time Directive. These times include 3 hours during nights on call which is probably a reasonable reflection of the amount of time that can be used effectively. These hours are based on a 9-year training programme (3 years as a basic surgical trainee and 6 years as a higher surgical trainee). If specialist training is reduced to 6 years ( 3 years basic and 3 years higher specialist training), the useful hours for training will reduce to just over 6000 hours, which is $21 \%$ of the time available prior to the mid $1990 \mathrm{~s}$ and $40 \%$ of the existing time. If it is reduced to 5 years, which is the recommended minimum in the European Union and the minimum laid down in Schedule 3 of the Healthcare and Associated Professions Draft Statutory Instrument, the effective time for training, education and gaining experienced will be reduced to 5000 hours.

As a result of the introduction of the 'New Deal' and the European Working Time Directive (EWTD), surgeons will have to be trained in fewer hours. The hours must be used productively for training and gaining experience and this will require an enormous amount of consultant input into these hours. This consultant expansion will not provide any increased throughput but will be essential to ensure that the consultants of the future continue to be fully trained. Training will need to be more structured and concentrated. Shaw ${ }^{10}$ calculated the impact the EWTD would have on service delivery.

Unfortunately, we do not have the consultants to do this. Probably the biggest problem with the introduction of the Calman training programme was the failure to expand the consultant numbers to those required to meet the training obligations. This applies to all surgical specialties. Within trauma and orthopaedics, there are currently 1205 consultants in England. The British Orthopaedic Association estimates that to meet the current requirements, 1995 consultants are required. The National Health Service Executive recommended that by 2009 there should be 2075 consultants. There is good evidence that not only in the next 6 years will there be an increasing demand for orthopaedic surgery and that the proposed numbers will not be sufficient, but also that the SpR expansion is not sufficient to meet these numbers. A rapid 


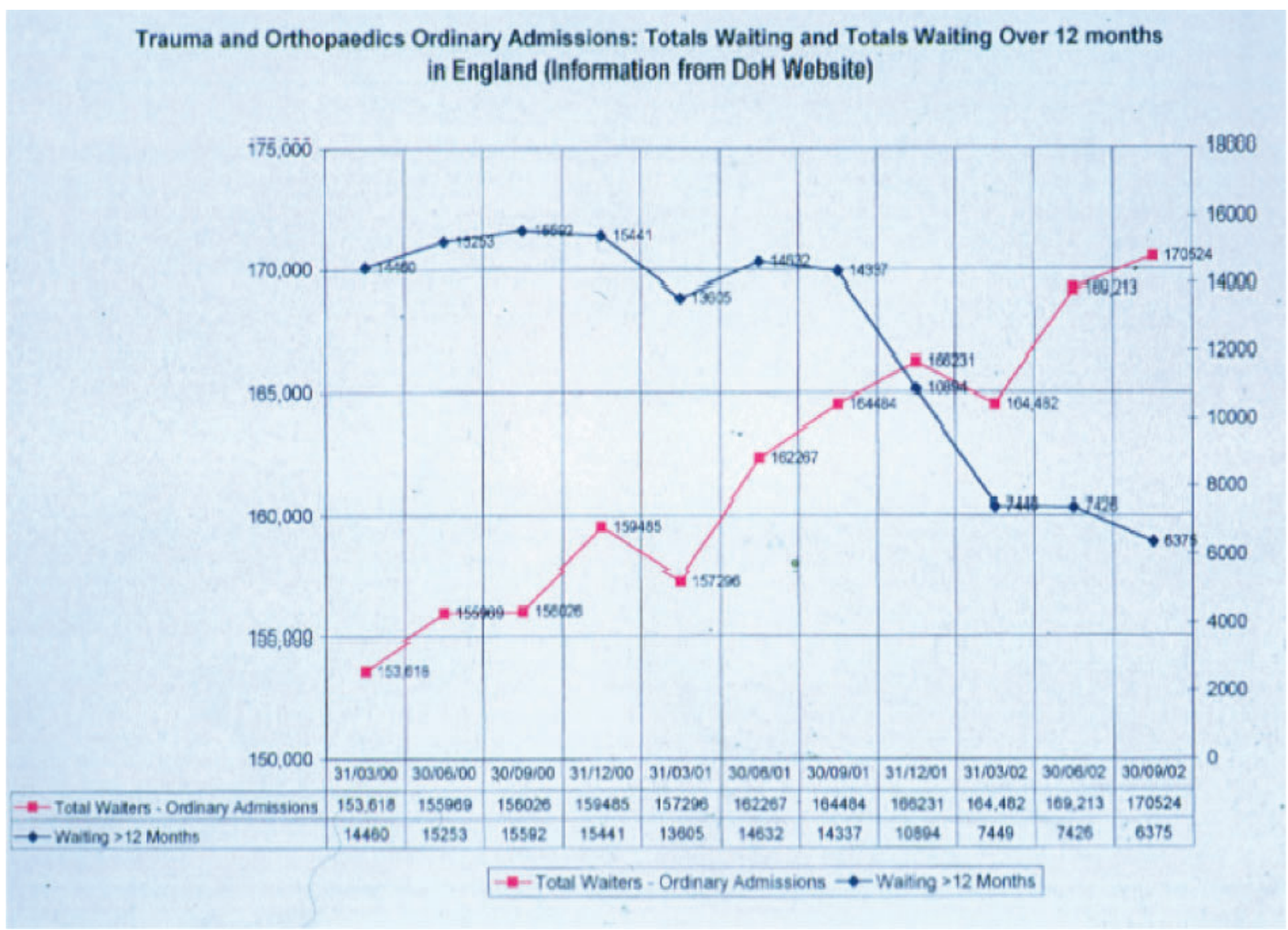

Figure 12 The number of patients on the waiting list for orthopaedic surgery. Although there has been a progressive decrease in the number of patients waiting over 12 months since September 2001, there has been a simultaneous increase in the total number of patients awaiting surgery. Chart produced from Provider Based Hospital Waiting List Statistics, Department of Health, England, www.doh.gov.uk/waitingtimes.

expansion of funded SpR numbers is urgently required, not only to meet the service demands but also to ensure that the training of the next generation of surgeons is adequate.

Training takes time. If a consultant operates, more cases can be done on a list. It is estimated, for example, that a trainee takes $45 \%$ longer than a consultant for an inguinal hernia, $29 \%$ for varicose vein surgery, $38 \%$ for laparoscopic cholecystectomy and $28 \%$ for carotid endarterectomy. ${ }^{11}$ Training must be progressive and in terms of operative experience it means that the trainee must progress from minor through intermediate and major procedures to complex major procedures. Within each category, the trainee needs to proceed from assisting, doing the operation or part of the operation with assistance, undertaking the operation under supervision and then carrying out the operation unsupervised but with the consultant easily available if required. This takes time and fewer procedures can be carried out on a training list than if the consultant was to undertake all the surgery alone.
During my Presidency of the British Orthopaedic Association, we started a survey on orthopaedic priorities, ethics and numbers. ${ }^{12}$ We asked a number of questions from 100 trusts representing all parts of the UK. Despite all the finances coming into the health service during the past 2 years, this has not helped trauma and orthopaedics, in that an increasing number of beds have been closed and there has been no reduction in the cancellation of elective operating lists. More patients have had their safety or quality of care compromised by inadequate staffing or bed numbers but the most important figure, as regards training, is the progressive negative effect the service need pressures are having on the training of the next generation of surgeons. In the 2001 questionnaire, we were told that in $34 \%$ of trusts the operative experience available to orthopaedic trainees had diminished as a result of pressure to reduce waits. This increased to $54 \% 12$ months later. This is exactly the opposite of what is required for training when there is a reduction in the number of available hours. 
Despite this, the total number of patients waiting for orthopaedic surgery has increased (Fig. 12), although there has been a reduction in the number of patients waiting for more than 12 months, indicating that the pressures on increasing workload will continue and are likely to continue to adversely affect training until there is an adequate expansion in the number of consultants and their resources.

\section{Potential changes in surgical training in this decade}

This will affect both basic surgical training and higher surgical training and may result in a single, 'run-through' specialist training programme. Many of the changes with respect to basic surgical training will come about as a result of Unfinished Business, the report from the Chief Medical Officer. This has suggested the introduction of a 2-year foundation programme, the first year of which will be equivalent to the current pre-registration house year*. The second year could be equivalent to year 1 of basic specialist training, depending on the posts through which the trainee rotates or it may be a more generic year before entering into basic specialist training. It may include posts in general practice, accident and emergency, intensive care medicine, etc. The duration of basic specialist training is likely to be reduced to a maximum of $2-3$ years, with a limited tenure thereafter in the $\mathrm{SHO}$ grade. Reform of the $\mathrm{SHO}$ grade must take account of poor job structure and the jobs must be part of a training rotation or programme; poorly planned training (there needs to be an end point); weak selection and appointment procedures; increasing workloads; inadequate supervision, assessment, appraisal and career advice; insufficient opportunities for flexible training; and the training needs of non-UK graduates. It was recommended that training should be programme-based; be broadly based to begin with for all trainees; provide individually-tailored programmes to meet specific needs; be time-capped; and support the movement of doctors into and out of training and between training programmes.

The four UK Health Ministers have considered the responses to the consultation on Unfinished Business (Modernising Medical Careers. The Response of the Four UK Health Ministers to the Consultation on Unfinished Business. Proposals for the Reform of the Senior House Officer Grade, 2003). They acknowledge the high standard of medical training in the UK but felt that there was significant room for improvement.

They proposed a major change in training which was based on a number of principles that included the production of a high quality, well trained and accredited doctor who could deliver the care and treatment patients needed in the modern NHS; preparation of the doctor to work in a multiprofessional environment; the organisation of postgraduate medical training in structured programmes with progress monitored against clear curricula; competency-based assessment; programmes to be designed and managed to ensure the trainees complete them in the minimum necessary time with explicit career pathways and explicit career goals; flexibility; training, as far as possible should be seamless; training must be supported by strong educational management and underpinned by skilled trainers; programmes should be broadly based at first and lead on to greater specialisation where appropriate; training should be trainee-centred, service based and quality assured. In many instances, new training systems would produce a new type of consultant who would not necessarily have been required to undergo 'deep specialisation' now found in a number of programmes. Whilst new arrangements would acknowledge that not every doctor had to undergo such lengthy training, it was clear that a significant cadre of consultants would be needed for more complex, specialised treatment.

As indicated above, the time for training will be reduced as a result of the European Working Time Directive and there will probably be the introduction of validated, but more robust, assessments. An Intercollegiate MRCS will replace the separate Collegiate MRCS examinations and it is probable that a Certificate of Completion of Basic Surgical Training will be a requisite before a trainee will be considered for entry into higher surgical training. If a single training grade is instituted, this will replace the interviews and gap period between basic surgical training and higher surgical training. Educational contracts will be routine and the Manual of Basic Surgical Training will be updated. In particular, the curriculum requires updating.

There may be improvements in our method of selecting trainees suitable for surgical training. At the moment, many more individuals enter surgical training and satisfactorily complete basic surgical training than can be accommodated in higher surgical training. This will disappear if a single training grade is introduced, in the same way that the Calman training programme removed the discrepancy between the number of registrars seeking $S p R$ appointments and the number of SpR posts available. Selection of the future consultants will be determined by the appointment to basic specialist training. If we are to select the best consultants for different specialties, we will need to improve our methods of selection.

If there is a further reduction in the duration of training, we may see the end of basic training in surgery in general and the creation of a North American-type model where individuals start specialty-specific training having completed a foundation programme.

* The 2-year foundation programme has been established, since the oration was delivered, and will start in 2005. 


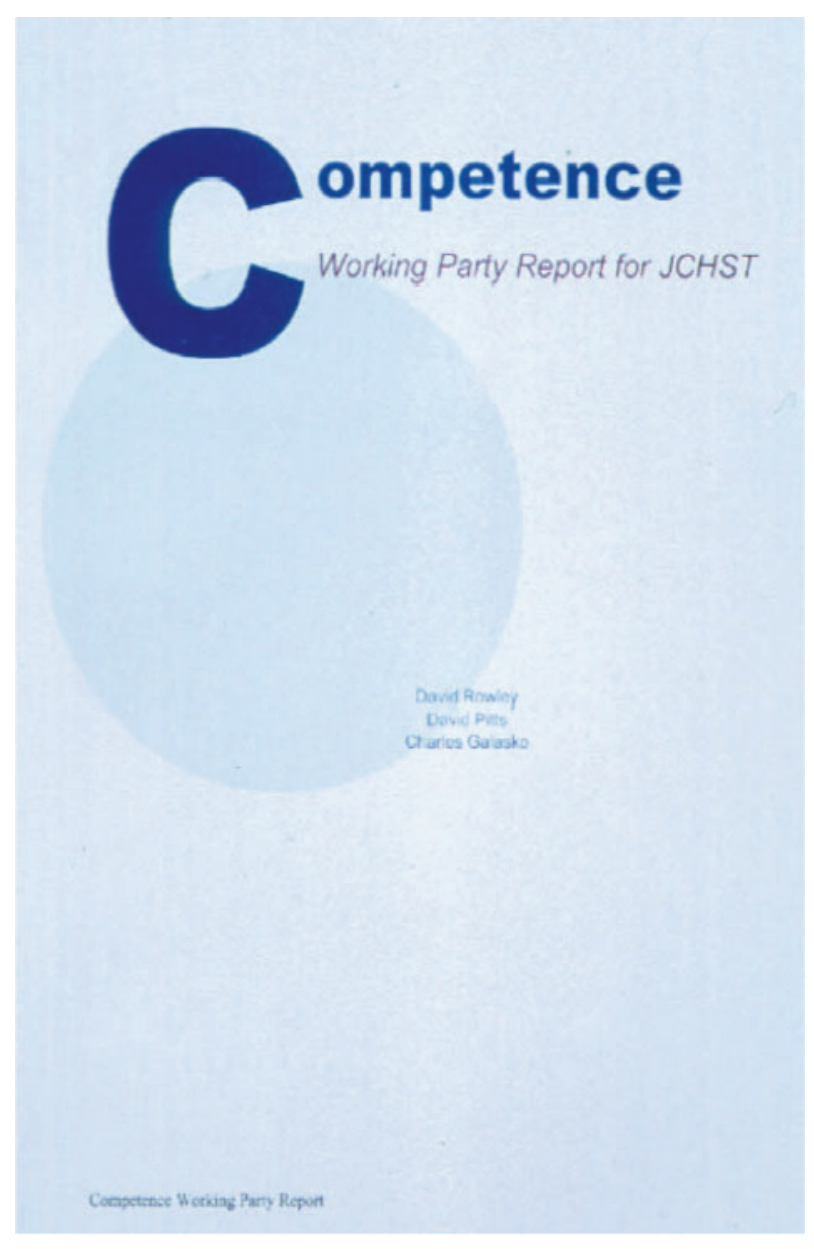

Figure 13 The Competence Working Party Report.

\section{Duration of training}

There are basically two types. The first is the current system based on a minimum specified number of years, currently 6 years in higher specialist training in most surgical specialties. The second is a competence-based training programme whereby the trainee has to develop the required competencies and once he/she has reached the necessary level they are considered to be trained. ${ }^{13}$

In their report, the Committee Chaired by Sir Rex Richards looking at clinical academic careers asked in July 1997 whether particularly talented individuals could achieve the competence required to be a consultant any sooner. In its response, the Joint Committee on Higher Surgical Training established a Competence Assessment Working Party under my chairmanship. The report was published last year (Fig. 13). ${ }^{14}$

We recommended that a competence-based training programme should be developed and that this should apply to all trainees, not just academic trainees. The competencies required to be a competent surgeon in the 21st century were defined. These included communication skills, knowledge of basic sciences, knowledge of clinical sciences, clinical skills, postoperative management, teaching skills including the skills of appraisal and assessment, learning skills including self-education, attitude which includes timemanagement, ethics, team working, leadership, etc., the ability to analyse data and interpret results critically, and management skills. The two most important competencies required are decision making and judgement, and surgical skills and manual dexterity. The major causes of litigation across all surgical specialties are intra-operative problems, incorrect or delayed diagnosis and failure to recognise complications. The Competence Assessment Working Party defined three phases of training. The concept is that the individual has to satisfactorily complete one phase of training before he/she can pass into the next stage. It was suggested that they should be:

- Half way through training in the generality of the specialty. That is approximately equivalent to the end of year 2 on the current higher specialist training programme

- At the end of training in the generality of the specialty which is roughly equivalent to the end of year 4

- At the end of training. There are two aspects to this third phase. First it gives the trainee the time and opportunity to gain experience in decision making, judgement and operative skills in the generality of his or her specialty as well as to start training in the subspecialty of their choice. This is roughly equivalent to the end of year 6 and during this period the individual should pass the Intercollegiate Fellowship Examination. This period to gain experience is vital. It would be unacceptable to expect a surgeon to be supervised for 3 years and 364 days and suddenly at 3 years and 366 days to be able to carry out operations competently on his or her own, even if a colleague was acting as a mentor.

In such a competence-based training programme, the number of years of training are not specified and the weekly hours of work are not primarily important. Trainees progress at their own rate and trainees who take longer will not be regarded as a 'failure'. In the current training programme, if a trainee's progress is slow. he/she may require 'remedial' training. The CCT will indicate that the individual is competent and, providing that the assessments are validated and sufficiently robust, inadequate trainees should be assessed earlier and suitably counselled.

The Competence Assessment Working Party looked at assessment in some detail. It recommended that the number of formal examinations should not be increased; that for the foreseeable future assessment should include a formal examination in the generality of surgery as part 
of the requirement for entry into higher surgical training; that for the foreseeable future a specialty-specific formal examination should continue but that the timing of the examination and the details may change; and that the main assessment will continue to be the workplace assessment. A number of pilot studies were carried out to determine whether external assessors should play a role in the workplace assessment. The trainees found them highly stressful despite knowing that it was a pilot scheme. It was very time consuming for the external assessors and, therefore, very expensive. The external assessors, all of whom were experienced trainers and examiners, described the exercise as no less artificial than the current examination structure and their assessment was no different to that of the trainee's own trainer who, in this exercise, were all highly experienced. The pilot study stressed the importance of training consultants in methods of assessment so that internal workplace assessments can be fair, robust and validated. External assessment may be necessary before someone is counselled out of surgery. Finally, the working party agreed that a basket of assessments is necessary to include the membership examination, the fellowship examination, workplace assessments at the end of each post and the portfolio (see below).

Assessment in the workplace needs to be a continuing assessment - in the out-patient clinic, on the ward and in the operating theatre. It assesses the knowledge, communication skills, clinical skills, decision-making and judgement and surgical skills of the trainee. It must be consistent and capable of validation.

The Competence Assessment Working Party also developed a new training assessment form and proposed that each trainee should keep a portfolio and indicated its contents.

The recommendations of the working party were accepted by the Joint Committee in Higher Surgical Training, were accepted by the Specialist Training Authority Implementation Group and formed the basis of the approach to competence training by many of the medical Royal Colleges.

\section{Probable changes in this decade}

Although Unfinished Business is primarily about proposals for reform of the $\mathrm{SHO}$ grade, it also made suggestions about higher surgical training. As indicated above, it suggested that the pre-registration house officer year should be enlarged to a foundation programme of 2 years. Trainees would then enter basic specialist training by competition. This would last for 2-3 years, possibly extended for a further year but it would be time-limited. Trainees would then either move into a higher specialist training programme or into a career-grade post.

There also was the suggestion that higher specialist training should be divided into two parts. The first part which is likely to last for 3-5 years would train the individual in the generality of his/her specialty at the end of which time they would become a specialist able to handle emergencies (equivalent to the end of phase 2 of training as defined by the Competence Assessment Working Party but also including part of phase 3 to allow them to gain the experience to treat the emergencies which are often the most difficult problems in surgery). A proportion would subsequently undergo training in a subspecialty and obtain a second Certificate of Completion of Training. It suggested that the CCST should be replaced by a CCT (Certificate of Completion of Training).

It also raised the question of whether a single training grade should be introduced.

The changes in higher surgical training over the past 10 years have been dramatic and the pace of change is likely to increase this decade. The role of a consultant will change. John F Kennedy noted: 'Change is the law of life. And those who look only to the past or the present are certain to miss the future.' It is essential that training is modified as necessary to ensure that the consultant in the future is 'fit for purpose'. First, we have to define the end product required and must include reflective practice and sound judgement. Once, we have defined the clinical context, we then need to define the level of expertise within each competency, the levels of expertise required at each phase of training and the methods of assessment for each competency and at each phase of training. We need to develop validated learning contracts and a log book of operative and clinical experience which is both reflective and a record of their experience. The competencies required to be a competent surgeon will depend on the end product required. We need to develop validated tools to assess operative and clinical skills. This may be prescriptive performance-based or on a global assessment. There needs to be transparent, objective and regular appraisals. A competence map to link all aspects of training and assessment needs to be developed. I believe that we should move to a competence-based training programme and away from a programme that is based on a specified minimum number of years. This also requires the development of robust, validated and objective training post assessments. Above all, we need the necessary resources for training and to allow trainees to gain experience in addition to those required for service needs.

This means that service needs cannot and must not take priority over education. Both require adequate resources and funding to ensure that surgery is provided with the resources, the staff and the facilities, the time and the educational support to meet both the service needs and the educational and training needs of our trainees and that their training and education makes them competent to be surgeons in the 21st century. Without research, in one generation the specialty will not grow; without training and education, in one generation there will be no specialty. 


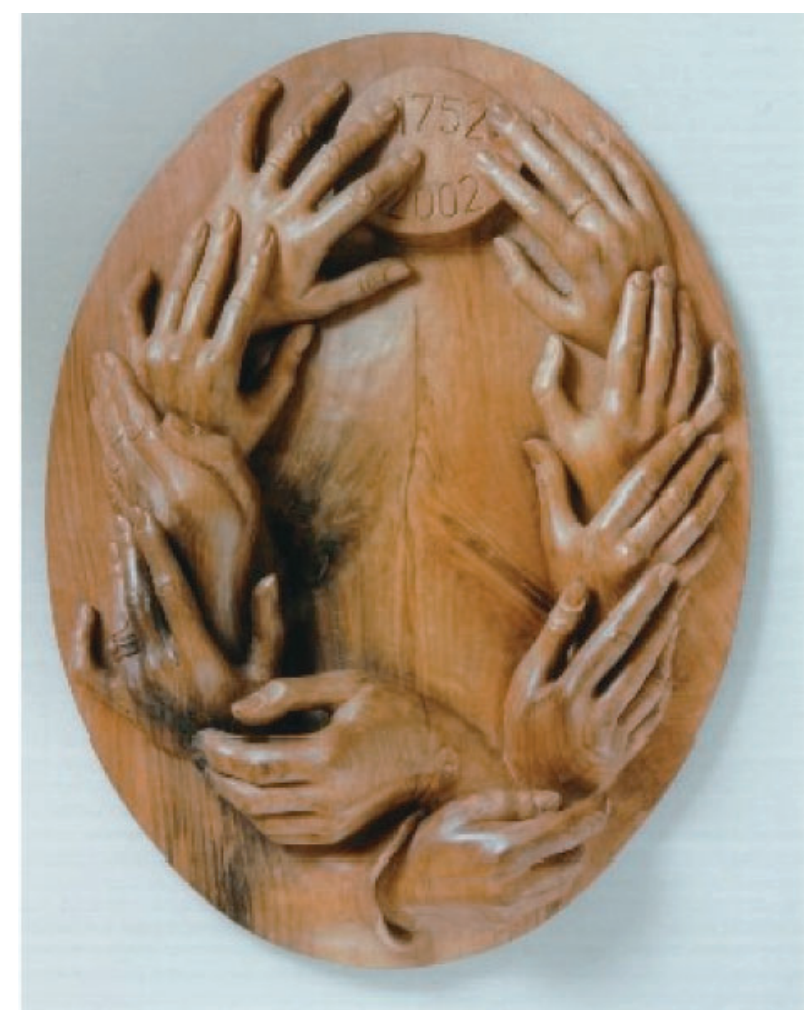

Figure 14 Sculpture by Elona Bennett Handing on Skills, Ideas and Ideals. The piece symbolises the passing on of theory and clinical expertise over St George's Hospital Medical School's history. It consists of life-size hands. Two of the hands are those of John Hunter and Edward Jenner, who was one of his students. The other hands are from individuals who are currently involved in education and training such as Professor Robert Boyd, the Principal of St George's Hospital Medical School. (Published with the permission of St George's Hospital Medical School.)

Figure 14 (published with the permission of St George's Hospital Medical School) is of a sculpture Handing on Skills, Ideas and Ideals which was unveiled at St George's Hospital Medical School in December 2002 to celebrate its 250th anniversary. It is carved in English walnut by Elona Bennett, the piece symbolising the passing on of theory and clinical expertise over the Medical School's history. Two of the hands, which are all life-size, are those of John Hunter and Edward Jenner, who was one of his students. The other hands are from individuals who are currently involved in education and training such as Professor Robert Boyd, the Principal of St George's Hospital Medical School. The sculpture symbolises the passing on of skills, ideas and ideals from one generation to the next. It starts with the hand of John Hunter, the father of scientific surgery.

We have inherited his legacy and it is our responsibility to make sure that we pass it on. It is our responsibility to ensure that the next generation of surgeons are well trained. If we fail to do so, we will fail the patients of the future and I believe that this legacy of John Hunter's is even more important than his legacy as the founder of scientific surgery.

\section{Acknowledgements}

I am grateful to Simon Chaplin, Hunterian Museum, The Royal College of Surgeons of England; Tina Craig, Librarian, The Royal College of Surgeons of England and Valerie Haigh, Librarian, Salford Royal Hospitals NHS Trust for their help.

\section{References}

1. Hunter J. Lectures in the Principles of Surgery.

2. Finch $E$. The influence of the Hunters in medical education (Hunterian Oration). Ann R Coll Surg Engl 1957; 20: 205-248.

3. Finney JMT. The influence of John Hunter on early American surgery. Lancet 1927; 1: 420.

4. Middleton WS. John Morgan, father of medical education in North America. Ann Med Hist 1927; 9: 13-26.

5. Middleton WS. Philip syng Physick, father of American surgery. Ann Med Hist 1928; 3 ser 1: 562-582.

6. Brockbank EM. The Foundation of Provincial Medical Education in England. Manchester: Manchester University Press, 1936.

7. Burgess AH. Development of provincial medical education illustrated in the life and work of Charles White of Manchester (Hunterian Oration). Lancet 1941; 1: 235-240.

8. British Orthopaedic Association. Education and Training for SHOs. A Snapshot of the Moment and Recommendations for the Future. A report from the Academic Board of Orthopaedic Surgery. London: British Orthopaedic Association, 2002.

9. de Cossart L, Wiltshire C, Brown J. An audit of the operative skills of SHOs on a BST programme. Ann R Coll Surg Engl (Suppl) 2001; 83: 326-327.

10. Shaw MDM. The Working Time Directive: the potential impact on a neurosurgical centre's medical manpower and service delivery from 2004. Br J Neurosurg 2002; 16: 6-9.

11. Sudhindran S, Edwards PR. Surgical training takes time. Ann R Coll Surg Engl (Suppl) 2001; 83: 196-197, 202.

12. Galasko C, Macnicol M, Meade A. A failing system; orthopaedic services in the NHS 2001-2002. BON 2003; 7: 8-9.

13. Galasko CSB. Assessment of professional, clinical and surgical skills in the workplace. In: Surgical Competence. Challenges of Assessment in Training and Practice. London: The Royal College of Surgeons of England and the Smith and Nephew Foundation 1999; 126-147.

14. Rowley D, Pitts D, Galasko CSB. Competence Working Party Report for JCHST. London: Joint Committee on Higher Surgical Training, 2002 <www.jchst.org>.

\section{General reading}

Committee of Vice-Chancellors and Principals. Report of task force in clinical academic careers (Chairman Sir Rex Richards). London: CVCP, 1997.

Department of Health and Social Security. Hospital Medical Staffing: Achieving a Balance. The 'Plan for Action' in Brief. London: DHSS, 1988.

Department of Health. Hospital Doctors; Training for the Future. The Report of the Working Group in Specialist Medical Training (Calman Report). London: DoH, 1993.

Department of Health. Modernising Medical Careers. The response of the four UK Health Ministers to the Consultation on Unfinished Business; 
Proposals for reform of the Senior House Officer Grade. London: DoH, 2003 $<$ www.doh.gov.uk/consultations/responses.htm>.

Department of Health. Unfinished Business; Proposals for Reform of the Senior House Officer Grade. London: DoH, 2002,

$<$ http://www.doh.gov.uk/shoconsult/>.

General Medical Council. Implementing The New Doctor. London: GMC $2002<w w w . g m c-u k . o r g>$

Hunter J. Hunter Works, 1766; 1: 264, 436-439.

Joint Committee on Higher Surgical Training. A Manual of Higher Surgical Training in the United Kingdom and Ireland, 7th Report. London: JCHST, 1999.

Joint Committee on Higher Surgical Training. A Manual of Higher Surgical Training in the United Kingdom and Ireland, 8th Report. London: JCHST, 2003 <www.jchst.org>.

NHS Executive. A Guide to Specialist Registrar Training ('Orange' Book). London: NHS, 1995.

NHS Executive. A Guide to Specialist Registrar Training ('Orange' Book). London: NHS, 1996.

NHS Executive. A Guide to Specialist Registrar Training ('Orange' Book). London: NHS, 1998.
NHS Management Executive. Junior Doctors, The New Deal, Working Arrangements for Hospital Doctors and Dentists in Training. London: DoH, 1991.

The European Working Time Directive. <www.doh.gov.uk/workingtime>.

The General Medical Practice and Specialist Medical Education, Training and Qualifications Order 2003. Consultation Document.

The Royal College of Surgeons of England. Basic Surgical Training and the Hospital Recognition Committee (The 'Blue' Book). London: RCSE, 1995.

The Royal College of Surgeons of England. Basic Surgical Training and the Hospital Recognition Committee (The 'Blue' Book). London: RCSE, 1997.

The Royal College of Surgeons of England. Manual of Basic Surgical Training. London: RCSE, 1998.

The Royal College of Surgeons of England. Handbook for College Assessors. London: RCSE, 1999.

The Royal College of Surgeons of England. Handbook for Regional Advisers and Regional Specialty Advisers. London: RCSE, 1999.

The Royal College of Surgeons of England. Handbook for Surgical Tutors. London: RCSE, 1998.

The Royal College of Surgeons of England. The Curriculum Framework for the General Professional Practice of Surgery. The first three years (draft). London: RCSE, 2003. 